\title{
Height growth of black spruce in British Columbia
}

\author{
by Gordon D. Nigh ${ }^{1}$, Pavel V. Krestov² and Karel Klinka ${ }^{3}$
}

Black spruce (Picea mariana (Mill.) B.S.P.) is a boreal species that occurs extensively across the northern half of British Columbia. Forest managers require better growth and yield information for black spruce given the anticipated increase in demand for wood in the northern part of the province. The purpose of this study was to develop height-age models for black spruce. Ninety-one stem analysis plots were established in the BWBS and SBS biogeoclimatic zones. Three black spruce site trees from each plot were stem analyzed and the data were converted into height-age data. A conditioned log-logistic function was fit to the data. Indicator variables were used to test for differences in height growth between the sampled subzones. Although the warm subzones had different height growth patterns than the cool subzones, there was general agreement among the height-age models from British Columbia, Alberta, and New Brunswick up to about age 100 .

Key Words: biogeoclimatic zones, height-age models, logistic function, site index, stem analysis

L'épinette noire (Picea mariana (Mill.) B.S.P.) est une espèce boréale qu'on retrouve fréquemment dans la partie nord de la Colombie-Britannique. Les aménagistes forestiers ont besoin d'information plus précise sur la croissance et le rendement de l'épinette noire étant donné un accroissement anticipé de la demande de matière ligneuse dans la partie nord de la province. L'objectif de cette étude était d'élaborer des modèles hauteur-âge pour l'épinette noire. Quatre-vingt-onze analyses de tige ont été réalisées dans les zones biogéoclimatiques BWBS et SBS. Les tiges de trois épinettes représentatives de chacune des parcelles ont été étudiées et les données ont été converties en données sur la hauteur-âge. Une fonction logistique logarithmique a été adaptée aux données. Des variables indicatrices ont été utilisées pour évaluer les différences de croissance en hauteur entre les sous-zones échantillonnées. Même si les sous-zones chaudes avaient des patrons de croissance différents par rapport aux sous-zones froides, les modèles hauteur-âge étaient généralement semblables que ce soit en Colombie-Britannique, en Alberta et au Nouveau-Brunswick jusqu'à l'âge de 100 ans.

Mots-clés: zones biogéoclimatiques, modèles hauteur-âge, fonction logistique, indice de station, analyse de tige

\section{Introduction}

Black spruce (Picea mariana (Mill.) B.S.P.) is a principal tree species in the boreal forests of Canada. Its geographic range includes much of Canada and northeastern United States, although its commercial range is much less than its geographic range (Viereck and Johnston 1990). In British Columbia, black spruce occurs in the northern half of the province, mainly in the Boreal White and Black Spruce (BWBS), SubBoreal Spruce (SBS), and Spruce - Willow - Birch biogeoclimatic zones, and occasionally in the Sub-Boreal Pine - Spruce, and Interior Cedar-Hemlock zones (Meidinger and Pojar 1991).

In eastern Canada, black spruce is a valuable pulp species because of its long fibres, but is also used for lumber (Viereck and Johnston 1990). Black spruce is a less desirable crop species in BC, except on sites not suited for more desirable species such as white spruce (P. glauca (Moench) Voss) or lodgepole pine (Pinus contorta Dougl. ex. Loud.). Currently, foresters in British Columbia use black spruce height-age curves developed by the Alberta Forest Service (1985) to estimate the height and site index of black spruce. However, more local information about the growth and yield of black spruce is needed in antic-

${ }^{1}$ Research Branch, British Columbia Ministry of Forests, P.O. Box 9519, Stn. Prov. Govt., Victoria, British Columbia V8W 9C2. E-mail: Gordon.Nigh@gems2.gov.bc.ca

${ }^{2}$ Institute of Biology and Pedology, Russian Academy of Sciences, Far Eastern Branch, Vladivostok, Russia V690022. E-mail: krestov@ vtc.ru

${ }^{3}$ University of British Columbia, Department of Forest Sciences, 3041 - 2424 Main Mall, Vancouver, British Columbia V6T 1Z4. E-mail: klinka@pop.unixg.ubc.ca

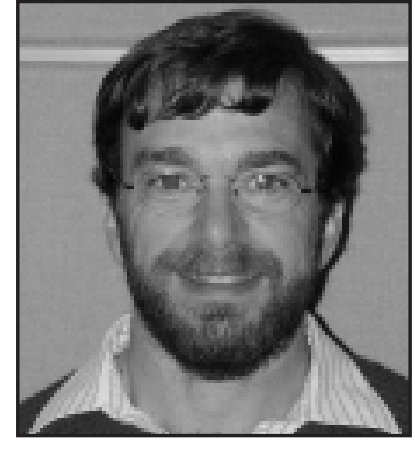

Gordon D.Nigh

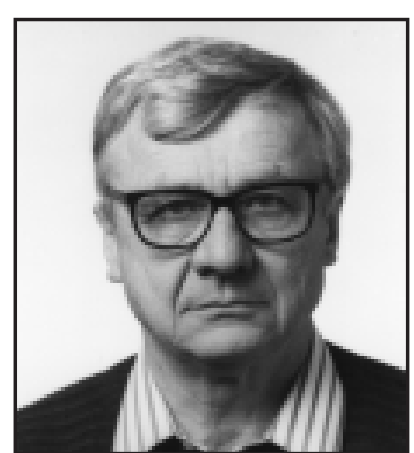

Karel Klinka ipation of more demands for the timber resources of the boreal forest in BC (Krestov et al. 2000).

Site index, which is a species-specific measure of site productivity, is an important parameter in growth and yield estimation. It is defined in $\mathrm{BC}$ as the average height of site trees at breast height age 50 . Site trees are the largest diameter, dominant or co-dominant trees of the target species. Their height growth must reflect the potential productivity of the site. Therefore, the trees must not have their height growth influenced by other non-site factors such as suppression or breakage. Breast height age is the number of annual growth rings at breast height $(1.3 \mathrm{~m})$.

The purpose of this study was to develop height-age (site index) curves for black spruce. Height-age curves estimate height from site index and breast height age. They also allow the estima- 


\begin{tabular}{|c|c|c|c|c|c|c|c|c|c|c|c|}
\hline \multicolumn{2}{|c|}{ Biogeoclimatic } & \multirow[b]{2}{*}{$\mathbf{n}$} & \multicolumn{3}{|c|}{ Site tree height $(\mathrm{m})$} & \multicolumn{3}{|c|}{ Breast height age (years) } & \multicolumn{3}{|c|}{ Site index (m@bha 50) } \\
\hline Zone & Subzone $^{\mathbf{a}}$ & & Mean & Minimum & Maximum & Mean & Minimum & Maximum & Mean & Minimum & Maximum \\
\hline BWBS & $\mathrm{dk}$ & 21 & 16.04 & 10.43 & 25.06 & 104 & 51 & 174 & 9.48 & 5.14 & 13.00 \\
\hline BWBS & $\mathrm{mw}$ & 50 & 14.52 & 8.03 & 22.11 & 90 & 52 & 155 & 9.90 & 4.98 & 17.09 \\
\hline BWBS & wk & 4 & 14.74 & 12.89 & 17.72 & 113 & 58 & 168 & 8.88 & 6.11 & 12.20 \\
\hline SBS & $\mathrm{dk}$ & 2 & 17.52 & 17.05 & 17.98 & 119 & 97 & 141 & 9.45 & 8.92 & 9.98 \\
\hline SBS & dw & 9 & 16.83 & 9.93 & 20.35 & 94 & 75 & 120 & 10.70 & 8.25 & 14.74 \\
\hline SBS & $\mathrm{mk}$ & 5 & 16.29 & 13.55 & 20.58 & 86 & 71 & 104 & 10.29 & 9.38 & 12.16 \\
\hline All & & 91 & 15.27 & 8.03 & 25.06 & 95 & 51 & 174 & 9.85 & 4.98 & 17.09 \\
\hline
\end{tabular}

aBWBSdk - Boreal White and Black Spruce zone, dry cool subzone.

BWBSmw - Boreal White and Black Spruce zone, moist warm subzone.

BWBSwk - Boreal White and Black Spruce zone, wet cool subzone.

SBSdk - Sub-Boreal Spruce zone, dry cool subzone.

SBSdw - Sub-Boreal Spruce zone, dry warm subzone.

SBSmk - Sub-Boreal Spruce zone, moist cool subzone.

tion of site index. These curves will provide information about growth and yield since volume is closely related to height. This study was part of a larger project investigating vegetation and soils of black spruce ecosystems and their productivity (Krestov et al. 2000).

\section{Data}

The target study area was nearly the entire BWBS zone and the northern portion of the SBS zone. Both zones are part of the Canadian Boreal Forest Region (Krajina 1969). The BWBS zone is influenced by a continental, montane boreal climate and subject to frequent occupation by arctic air masses. The climate influencing the SBS zone is slightly less continental, with lower temperatures in summer, higher temperatures in winter and a slightly longer growing season (Meidinger and Pojar 1991). Forest fires are frequent in both zones, which maintains a large portion of the landscape in early and mid-seral stages.

Plots were established in ecosystems deliberately chosen to obtain the widest possible range in environmental conditions, including climate, soil moisture and nutrients, and soil aeration, and to avoid trees with suppression above breast height. All plots were in fire-origin stands with a uniform single-canopy layer dominated by black spruce, but often contained other species, most commonly white spruce, lodgepole pine, or trembling aspen (Populus tremuloides Michx.).

The sample plots were $20 \mathrm{~m} \times 20 \mathrm{~m}$ and were located in naturally established, even-aged stands between 35 and 185 years at breast height age. One hundred and twenty-two plots were established but some were too young for height-age modelling (they must be at least 50 years breast height age so that the site index can be determined) or the height growth pattern of the trees indicate that some non-site factor was influencing their growth, making them unusable because their site index would be biased. The site, soil, and vegetation were described according to Luttmerding et al. (1990). The biogeoclimatic subzone was identified, and soil moisture and nutrient regimes were estimated for each plot using regional field guides (DeLong et al. 1990, Banner et al. 1993). Biogeoclimatic subzone is a basic unit of zonal classification - it represents a regional ecosystem, i.e., a group of geographically adjacent local ecosystems influenced by a particular regional climate (Meidinger and Pojar 1991).

The three largest diameter black spruce trees in the plot were found and checked for suitability. Suitable trees are those that are dominant or co-dominant and have no visible evidence of growth abnormalities or damage so that their height growth reflects the potential productivity of the site. The three site trees were then felled and their heights were accurately measured. The stems were sectioned at $0.3 \mathrm{~m}$ (stump height), $0.8 \mathrm{~m}, 1.3 \mathrm{~m}$, and then at 1-metre intervals along the stem. The rings were counted along two radii under magnification. Further information about the sampling and study plots can be found in Krestov et al. (2000).

\section{Methods}

The section height-ring count data were converted into height-age data using the algorithm proposed by Carmean (1972) and later modified by Newberry (1991). Individual tree and plot average height growth were graphed to detect suppression or other height growth abnormalities. Suppressed trees or trees with abnormal height growth patterns were deleted from further analyses. These trees were identified by slow growth followed by rapid height growth. Some deleted trees had rot at breast height, making a ring count impossible. Excluding trees that were too young, 47 trees were deleted, 12 from the BWBSdk, 27 from the BWBSmw, 6 from the BWBSmk, 1 from the BWBSwk, and 1 from the SBSdw zone. Ninety-one plots were available for height-age/site index modelling. Table 1 summarizes the height, breast height age, and site index information for these plots.

The data were split into a model calibration (47 plots) and a model testing (44 plots) data set. The splitting was done randomly and with the intent of having half the plots in the calibration and half the plots in the testing data sets (Snee 1977). The data were evenly split within each subzone, although no explicit attempt was made to achieve this goal. The log-logistic function provided the base for the height-age model (equation 1). This function has been used successfully in modelling height for other species (e.g., Thrower and Goudie 1992, Nigh 1997, Chen and Klinka 2000).

[1] $H_{i, A}=1.3+\left(S_{i}-1.3\right) \times b_{1} \div b_{2}+\varepsilon_{i, A}$

where $\mathrm{b}_{1}=1+\mathrm{e}^{\mathrm{a}_{0}+\mathrm{a}_{1} \times \ln (49.5)+\mathrm{a}_{2} \times \ln \left(\mathrm{S}_{\mathrm{i}}-1.3\right)}, \mathrm{b}_{2}=1+\mathrm{e}^{\mathrm{a}_{0}+\mathrm{a}_{1} \times}$ $\ln (\mathrm{A}-0.5)+\mathrm{a}_{2} \times \ln \left(\mathrm{S}_{\mathrm{i}}-1.3\right), \varepsilon_{\mathrm{i}, \mathrm{A}}$ is random error for plot $\mathrm{i}$ at age $\mathrm{A}$, $\mathrm{H}_{\mathrm{i}, \mathrm{A}}$ is site height ( $\mathrm{m}$ ) of plot $\mathrm{i}$ at age A, $\mathrm{S}_{\mathrm{i}}$ is site index (m @ bha 50) of plot i, A is breast height age (years), $a_{0}, a_{1}$, and $a_{2}$ are model parameters, $\mathrm{e}$ is the base for natural logarithms, and 
$\ln$ is the natural logarithm. The half-year adjustment in age removes a bias in model (1). The trees are shorter than $1.3 \mathrm{~m}$ (breast height) at breast height age zero, but without this adjustment equation (1) approaches $1.3 \mathrm{~m}$ as age approaches zero.

Equation (1) was fit to the height-age data using data at 5year intervals, starting at age 5 years. The data at age 50 years were deleted because the model is constrained: $\mathrm{H}=\mathrm{S} @ 50$ years. The model is also constrained to be $1.3 \mathrm{~m}$ as age approaches 0.5 years. The residuals $\left(\varepsilon_{\mathrm{i}, \mathrm{A}}\right.$ 's) were serially correlated and were neither normally distributed nor had a constant variance. In other words, three of the four standard regression assumptions (i.e., the residuals are independent and normally distributed with mean 0 and constant variance (Sen and Srivastava 1990)) were violated. Ensuring that these assumptions are met is important because we required reliable asymptotic confidence intervals (Seber and Wild 1989) to test for differences in height growth patterns across ecological zones and subzones. A violation of these assumptions does not bias the parameter estimates, but it does bias the variance and hence confidence intervals (Sen and Srivastava 1990). We converted the height model into a height growth model and incorporated a model for the serial correlation into the error term to correct some violations of the assumptions (Nigh 1997).

Equation (1) was converted into a growth model by approximating the first derivative with respect to age using the centred difference method with a step size of 0.5 year (Greenspan and Benney 1973), resulting in equation (2). Essentially, this method approximates growth at age A- 0.5 by subtracting the height at age A- 1 from the height at age A. Taking the derivative is not overly difficult (see Nigh 1997), but since the height data are converted into height growth data by the centred difference method as well, equation (2) and the data are compatible. This would not be the case if equation (2) were derived using calculus. A small, but practically insignificant, error would be introduced by using different methods to obtain the equation for growth.

[2] $H g_{i, A}=\left(S_{i}-1.3\right) \times b_{1} \times\left(b_{2}^{-1}-b_{3}^{-1}\right)+\varepsilon_{i, A}$

where $\mathrm{Hg}_{\mathrm{i}, \mathrm{A}}$ is the height growth of plot $\mathrm{i}$ at age $\mathrm{A}, \mathrm{b} 3=1+\mathrm{e}^{\mathrm{a} 0}$ $+\mathrm{a}_{1} \times \ln (\mathrm{A}-1.5)+\mathrm{a}_{2} \times \ln \left(\mathrm{S}_{\mathrm{i}}-1.3\right)$

We assume that the errors ( $\varepsilon_{\mathrm{i}, \mathrm{A}}$ 's) follow an $\mathrm{AR}(1)$ (first-order autoregressive) process model. An AR(1) model with a random error term was added to equation (2) to account for serial correlation in the data that usually exists with stem analysis data, resulting in equation (3). The $\mathrm{AR}(1)$ process models the error at time $\mathrm{A}$ as a linear function of the previous error (Seber and Wild 1989, Sen and Srivastava 1990), that is, $\varepsilon_{\mathrm{i}, \mathrm{A}}=\phi \times \varepsilon_{\mathrm{i}, \mathrm{A}-5}$ $+\omega_{i, A}$.

[3] $H g_{i, A}=\left(S_{i}-1.3\right) \times b_{1} \times\left(b_{2}^{-1}-b_{3}^{-1}\right)+\phi \times \varepsilon_{i, A-5}+\omega_{i, A}$

where $\phi$ is the autocorrelation coefficient $(-1<\phi<1), \omega_{i, A}$ 's are normally distributed independent random errors with mean zero and constant variance.

We tested for differences in height growth patterns between the six subzones that we sampled (BWBSdk, BWBSmw, BWBSwk, SBSdk, SBSdw, and SBSmk) by expressing model parameters $\mathrm{a}_{0}, \mathrm{a}_{1}$, and $\mathrm{a}_{2}$ as a linear function of other parameters and indicator variables. The indicator variables take on the value of 0 or 1 , depending on which subzone the plot is located (equations (4a), (4b), and (4c)). [4a] $a_{0}=a_{00}+a_{01} \times \mathrm{BWBSmw}+a_{02} \times \mathrm{BWBSwk}+a_{03}$ $\times \mathrm{SBSdk}+a_{04} \times \mathrm{SBSdw}+a_{05} \times \mathrm{SBSmk}$

[4b] $a_{1}=a_{10}+a_{11} \times \mathrm{BWBSmw}+a_{12} \times \mathrm{BWBSwk}+a_{13}$ $\times \mathrm{SBSdk}+a_{14} \times \mathrm{SBSdw}+a_{15} \times \mathrm{SBSmk}$

[4c] $a_{2}=a_{20}+a_{21} \times \mathrm{BWBSmw}+a_{22} \times \mathrm{BWBSwk}+a_{23} \times \mathrm{SBSdk}$ $+a_{24} \times \mathrm{SBSdw}+a_{25} \times \mathrm{SBSmk}$

where BWBSmw $=1$ if the plot is from the BWBSmw subzone, 0 otherwise, BWBSwk $=1$ if the plot is from the BWBSwk subzone, 0 otherwise, SBSdk = 1 if the plot is from the SBSdk subzone, 0 otherwise, SBSdw $=1$ if the plot is from the SBSdw subzone, 0 otherwise, SBSmk = 1 if the plot is from the SBSmk subzone, 0 otherwise, and $\mathrm{a}_{\mathrm{i}, \mathrm{j}}, \mathrm{i}=0,1$, or $2, \mathrm{j}=0,1$, $2,3,4$, or 5 are model parameters.

Equations (4a), (4b), and (4c) were substituted sequentially into model (3) in place of parameters $\mathrm{a}_{0}, \mathrm{a}_{1}$, and $\mathrm{a}_{2}$, respectively and the model was re-fit. After re-fitting, indicator variables with similar parameter estimates were grouped. Two parameters were considered to be similar if the confidence interval for one contained the other parameter value. For example, if in equation (4a) parameters $\mathrm{a}_{01}$ and $\mathrm{a}_{02}$ had similar values, then they were grouped and the resulting equation is:

$$
\begin{aligned}
a_{0} & =a_{00}+a_{01} \times(\mathrm{BWBSmw}+\mathrm{BWBSwk})+a_{03} \times \mathrm{SBSdk} \\
& +a_{04} \times \mathrm{SBSdw}+a_{05} \times \mathrm{SBSmk}
\end{aligned}
$$

Parameters that were not significantly different from zero were deleted from the model.

Models (1), (3), and (3 with 4a, b, and c) were tested using the test data set. Heights were estimated with these models and were subtracted from the observed heights, resulting in the error in the height estimate. The mean overall error and the mean error by 5 -year age increment starting at breast height age 5 years and by subzone were calculated and tested for bias with a t-test.

\section{Results}

The fitting of models (1) and (3) was straightforward. The fitting of model ( 3 with $4 \mathrm{a}, \mathrm{b}$, and c) was somewhat more complicated. Only six parameters remained (equations $5 \mathrm{a}, 5 \mathrm{~b}$, and $5 c)$ after grouping and eliminating parameters in model (3/4a, $\mathrm{b}$, and $\mathrm{c})$ :

[5a $a_{0}=a_{00}+a_{01} \times(\mathrm{BWBSmw}+\mathrm{SBSdw})$

$[\mathbf{5 b}] a_{1}=a_{10}+a_{11} \times(\mathrm{BWBSmw}+\mathrm{SBSdw})$

[5c] $a_{2}=a_{20}+a_{21} \times(\mathrm{BWBSmw}+\mathrm{SBSdw})$

The results of the fitting of models (1), (3), and (3 with 5a, $\mathrm{b}$, and c) are presented in Table 2. All three models were unbiased (the mean errors, 0.033 for model $1,0.000093$ for model 3 , and 0.00023 for model 3 with $5 \mathrm{a}, \mathrm{b}$, and c, were not statistically significantly different from zero). However, based on the Shapiro-Wilk's W statistic (Shapiro and Wilk 1965), none of the models had normally distributed residuals. Fig. 1 and 2 are graphs of the residuals from models (1), (3), and (3/5a, b, c). They show that heteroscedasticity was reduced from model (1) to (3) to $(3 / 5 a, b, c)$. Although harder to see, the figures indicate that serial correlation was reduced as well. The lack of nor- 
Table 2. Results of the fitting of models $(1),(3)$, and (3/5) with the calibration data set

\begin{tabular}{|c|c|c|c|c|c|c|}
\hline \multirow[b]{2}{*}{ Model } & \multirow[b]{2}{*}{$\mathbf{n}$} & \multirow{2}{*}{$\begin{array}{l}\text { Root } \\
\text { MSE }\end{array}$} & \multirow[b]{2}{*}{ Parameter } & \multirow[b]{2}{*}{ Estimate } & \multicolumn{2}{|c|}{ 95\% Confidence Interval } \\
\hline & & & & & Lower & Upper \\
\hline$\overline{(1)}$ & 854 & 0.864 & $\begin{array}{l}a_{0} \\
a_{1} \\
a_{2}\end{array}$ & $\begin{array}{l}10.66 \\
-1.100 \\
-2.203\end{array}$ & $\begin{array}{l}10.01 \\
-1.132 \\
-2.416\end{array}$ & $\begin{array}{l}11.30 \\
-1.068 \\
-1.989\end{array}$ \\
\hline (3) & 916 & 0.0339 & $\begin{array}{l}a_{0} \\
a_{1} \\
a_{2} \\
\phi\end{array}$ & $\begin{array}{c}8.909 \\
-1.020 \\
-1.472 \\
0.5457\end{array}$ & $\begin{array}{c}7.547 \\
-1.048 \\
-2.063 \\
0.4889\end{array}$ & $\begin{array}{r}10.27 \\
-0.9927 \\
-0.8801 \\
0.6024\end{array}$ \\
\hline$(3 / 5 \mathrm{a}, \mathrm{b}, \mathrm{c})$ & 916 & 0.0333 & $\begin{array}{c}a_{00} \\
a_{01} \\
a_{10} \\
a_{11} \\
a_{20} \\
a_{21} \\
\phi\end{array}$ & $\begin{array}{l}10.37 \\
-3.349 \\
-1.091 \\
0.08543 \\
-2.001 \\
1.260 \\
0.5119\end{array}$ & $\begin{array}{c}9.347 \\
-4.880 \\
-1.152 \\
0.01504 \\
-2.332 \\
0.4874 \\
0.4537\end{array}$ & $\begin{array}{l}11.40 \\
-1.819 \\
-1.031 \\
0.1558 \\
-1.670 \\
2.032 \\
0.5700\end{array}$ \\
\hline
\end{tabular}

mality in the residuals should not invalidate t-tests for parameter significance because the t-test is fairly robust against moderate departures from the normality assumption (Mason et al. 1989). For all three models, the residuals are nearly normally distributed and their distribution is almost symmetrical. The means squared error and the $\mathrm{R}^{2}$ statistics are not reported because they are not directly comparable between the three models.

The results of the testing are presented in Table 3 and Fig. 3. Table 3 shows the overall mean error and the mean error by subzone, with the corresponding sample size, standard error, t-statistic for the t-test for bias, and its p-value for models (1), (3), and (3/5). Fig. 3 shows the mean error at five-year breast height age intervals for the same three models. The mean errors are connected by lines to show trends only: they do not imply that the errors were analyzed in a continuous manner.

The results of the model fitting and testing were somewhat inconclusive. The two growth models (models (3) and (3/5)) better met the regression assumptions, although this does not necessarily mean that they fit the data better. The analysis of model (3/5) strongly indicated that the height growth patterns in the BWBSmw and SBSdw subzones is different from the other subzones. The model testing is not that clear. Overall, model (3/5) has a smaller mean error. However, when the models are compared by subzone, model (3/5) does not perform as well in general as the other two models. Furthermore, when compared by age (Fig. 3), model (1) performs the best over the age range of most interest ( 50 to 100 years since rotation age would be in that range), with models (3) and $(3 / 5)$ performing about the same. The number of data points making up these graphs falls below ten at breast height age 120 . Consequently, the errors at ages above 120 years or so are highly variable and hence the results should be interpreted with caution at older ages.

After testing, the calibration and test data sets were combined and models (3) and (3/5) were re-fit with the expanded data set. The results of the re-fit are in Table 4 . Both models were unbiased, their residuals were homoscedastic and had no apparent serial correlation. There was evidence that the residuals were not normally distributed, but the departure from normality was, again, minor.

\section{Discussion}

This study resulted in new height-age models for black spruce in British Columbia. Two models were produced:

[6] $H=1.3+(S-1.3) \times \frac{1+e^{c_{1}}}{1+e^{c_{2}}}$

[7] $H=1.3+(S-1.3) \times$

$$
\frac{1+e^{9.086-1.052 \times \ln (49.5)-1.550 \times \ln (S-1.3)}}{1+e^{9.086-1.052 \times \ln (A-0.5)-1.550 \times \ln (S-1.3)}}
$$

where $\mathrm{c}_{1}=10.20-2.086 \times[\mathrm{BWBSmw}+\mathrm{SBSdw}]-(1.089-$ $0.05116 \times[\mathrm{BWBSmw}+\mathrm{SBSdw}]) \times \ln (49.5)-(2.017-$ $0.8619 \times[\mathrm{BWBSmw}+\mathrm{SBSdw}]) \times \ln (\mathrm{S}-1.3), \mathrm{c}_{2}=10.20-2.086$ $\times[\mathrm{BWBSmw}+\mathrm{SBSdw}]-(1.089-0.05116 \times[\mathrm{BWBSmw}+$ $\mathrm{SBSdw}]) \times \ln (\mathrm{A}-0.5)-(2.017-0.8619 \times[\mathrm{BWBSmw}+$ $\mathrm{SBSdw}]) \times \ln (\mathrm{S}-1.3)$.

Model (6) should be used if the site of interest is in one of the BWBSdk, BWBSmw, BWBSwk, SBSdk, SBSdw, or SBSmk subzones. Model (7) should be used if the site of interest is not in one of these subzones, or if the subzone is unknown. These models are graphed in Fig. 4. Note that the curve for site index 20 is not supported with data. It is shown for comparison and because it represents the upper limit of site index for black spruce. The use and interpretation of these curves for sites with site indices over $17 \mathrm{~m}$ should be done cautiously because they are not supported with data on those sites.

Indicator variables were used to test for differences in height growth patterns between subzones. Therefore, it was important to meet the regression assumptions so that the variance, and hence confidence intervals, for the parameter estimates are unbiased. Faulty conclusions about growth patterns could otherwise occur.

The analysis strongly showed that the growth patterns in the BWBSmw and SBSdw subzones differed from the growth patterns in the BWBSdk, BWBSwk, SBSdk, and SBSmk subzones. Relative to a zone, the BWBSmw and SBSdw subzones are warmer (as indicated by the $w$ in the subzone code), compared to the other subzones that are cooler (as indicated by the $k$ in 

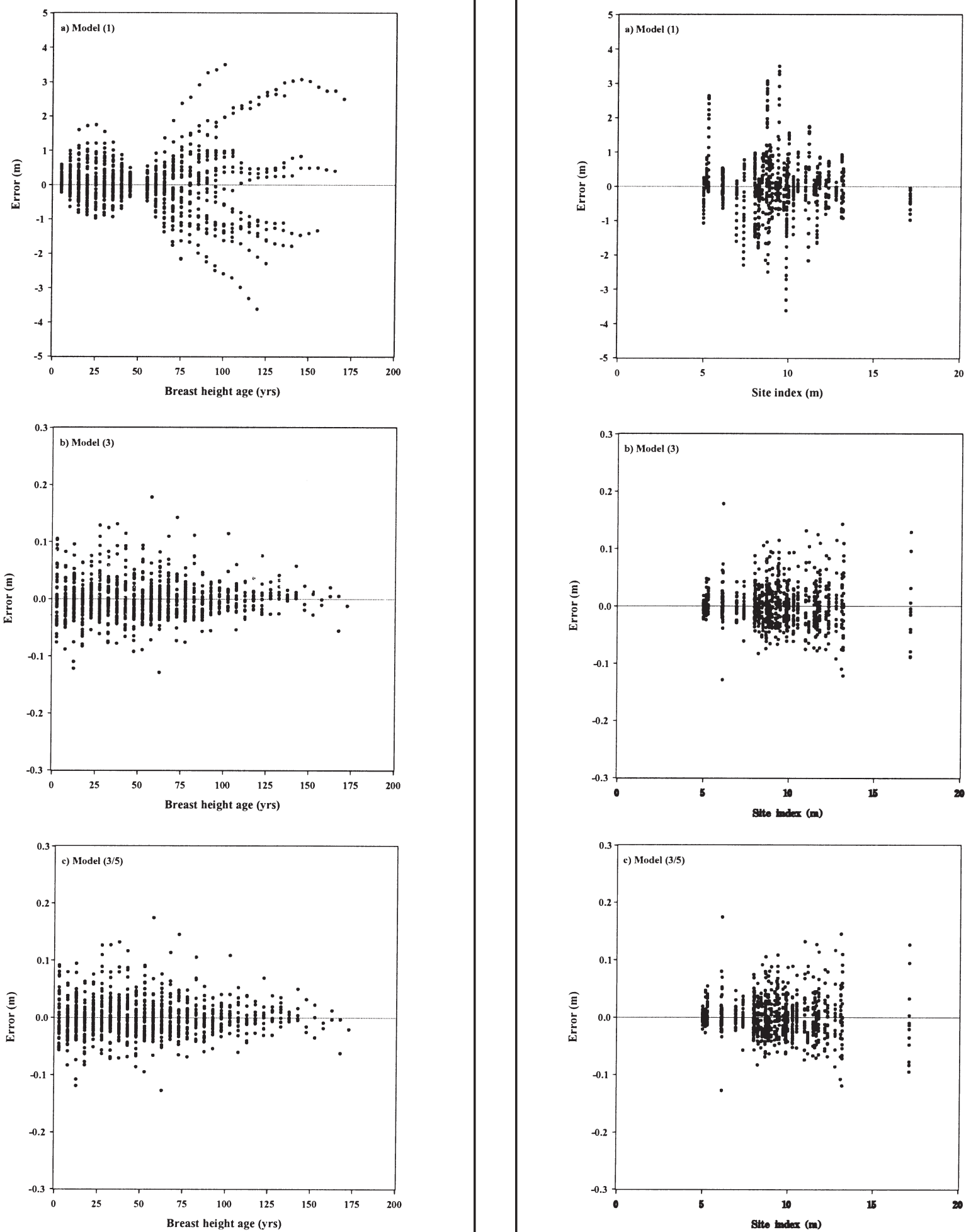

Fig 1. Residuals plotted against breast height age for models (1), (3), and $(3 / 5)$.

the subzone code). Height growth below breast height age 75 is almost identical across the subzones sampled in this study. However, at older ages, growth in the warmer subzones is slower than growth in the cooler subzones on poorer sites, but is faster on better sites. The largest divergence in growth occurs on the site index 20 curves, but it should be noted that no plots had a site index this high so these curves are extrapolated. All the plots except for one had site indices between approximately 5 


\begin{tabular}{|c|c|c|c|c|c|c|}
\hline Subzone & Model & $\begin{array}{c}\text { Mean } \\
\text { error }(m)\end{array}$ & $\begin{array}{c}\text { Sample } \\
\text { size }\end{array}$ & $\begin{array}{c}\text { Standard } \\
\text { error of the } \\
\text { mean }(\mathbf{m})\end{array}$ & t-statistic & p-value \\
\hline \multirow[t]{3}{*}{ All } & (1) & -0.1434 & 743 & 0.03229 & -4.442 & 0.0001 \\
\hline & (3) & -0.08183 & 743 & 0.03185 & -2.569 & 0.0104 \\
\hline & $(3 / 5)$ & -0.06919 & 743 & 0.03694 & -1.873 & 0.0615 \\
\hline \multirow[t]{3}{*}{ BWBSdk } & (1) & -0.1339 & 206 & 0.06875 & -1.947 & 0.0529 \\
\hline & (3) & -0.1208 & 206 & 0.07732 & -1.563 & 0.1196 \\
\hline & $(3 / 5)$ & -0.1952 & 206 & 0.07798 & -2.503 & 0.0131 \\
\hline \multirow[t]{3}{*}{ BWBSmw } & (1) & -0.07113 & 381 & 0.03410 & -2.086 & 0.0377 \\
\hline & (3) & -0.01459 & 381 & 0.03053 & -0.4781 & 0.6329 \\
\hline & $(3 / 5)$ & 0.08868 & 381 & 0.03410 & 2.601 & 0.0097 \\
\hline \multirow[t]{3}{*}{ BWBSwk } & (1) & -0.8738 & 39 & 0.1938 & -4.508 & 0.0001 \\
\hline & (3) & -0.5686 & 39 & 0.1137 & -5.000 & 0.0001 \\
\hline & $(3 / 5)$ & -0.8857 & 39 & 0.2027 & -4.369 & 0.0001 \\
\hline \multirow[t]{3}{*}{ SBSdk } & (1) & -0.9852 & 27 & 0.1956 & -5.036 & 0.0001 \\
\hline & (3) & -0.7075 & 27 & 0.1264 & -5.599 & 0.0001 \\
\hline & $(3 / 5)$ & -1.100 & 27 & 0.2216 & -4.964 & 0.0001 \\
\hline \multirow[t]{3}{*}{ SBSdw } & (1) & 0.1382 & 75 & 0.1144 & 1.209 & 0.2307 \\
\hline & (3) & 0.1733 & 75 & 0.1396 & 1.241 & 0.2184 \\
\hline & $(3 / 5)$ & 0.2813 & 75 & 0.1655 & 1.700 & 0.0934 \\
\hline \multirow[t]{3}{*}{ SBSmk } & (1) & -0.1058 & 15 & 0.1362 & -0.7766 & 0.4503 \\
\hline & (3) & -0.1374 & 15 & 0.1756 & -0.7822 & 0.4471 \\
\hline & $(3 / 5)$ & -0.1230 & 15 & 0.1224 & -1.005 & 0.3321 \\
\hline
\end{tabular}

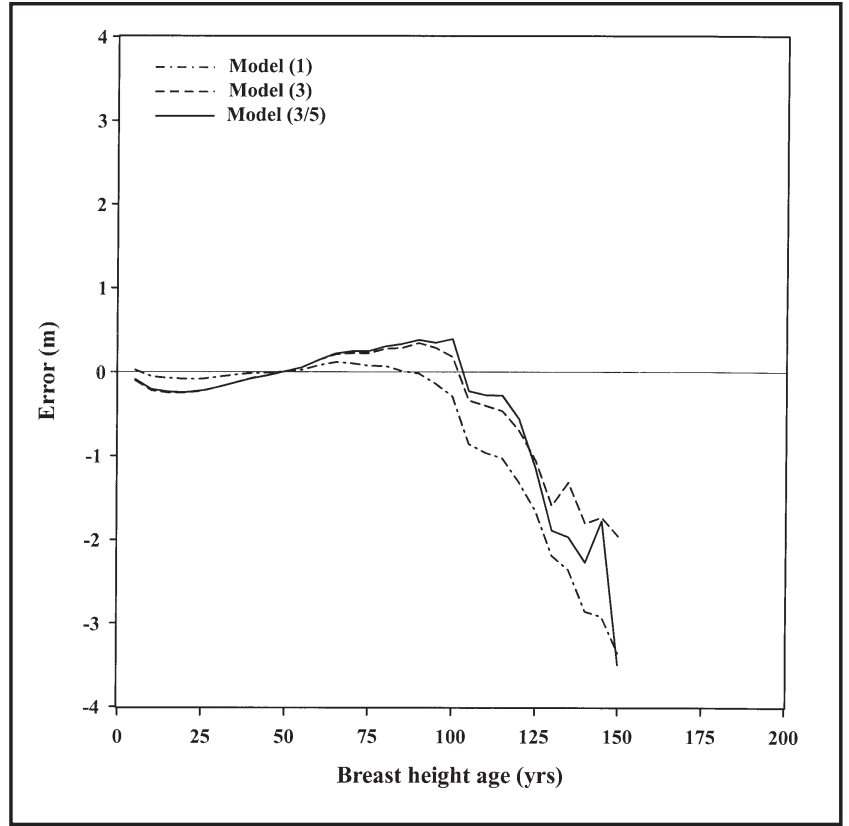

Fig. 3. Mean error of models (1), (3), and (3/5) plotted against breast height age.

and $15 \mathrm{~m}$, the other plot had a site index of around $17 \mathrm{~m}$. Therefore, the models are not well supported by data above site indices of around $15 \mathrm{~m}$.

Only three subzones are well represented by plot data in this study-BWBSdk $(\mathrm{n}=21)$, BWBSmw $(\mathrm{n}=50)$, and SBSdw $(n=9)$. The BWBSdk subzone, located in the rain shadow of the Coast Mountains, delineates the influence of a dry and cool montane boreal climate (mean annual temperature $-0.7^{\circ} \mathrm{C}$, mean annual precipitation $426 \mathrm{~mm}$ ); the BWBSmw subzone, located east of the Rocky Mountains, delineates the influence of somewhat wetter and warmer montane boreal climate (mean annual temperature $0.9^{\circ} \mathrm{C}$, mean annual precipitation $480 \mathrm{~mm}$ )
Table 4. Results of the re-fitting of models (3) and (3/5) with the full data set

\begin{tabular}{lcccc}
\hline & & & \multicolumn{2}{c}{ 95\% Confidence Interval } \\
\cline { 4 - 5 } Model & Parameter & Estimate & Lower & Upper \\
\hline$(3)$ & $\mathrm{a}_{0}$ & 9.086 & 8.392 & 9.779 \\
& $\mathrm{a}_{1}$ & -1.052 & -1.078 & -1.026 \\
& $\mathrm{a}_{2}$ & -1.550 & -1.770 & -1.331 \\
& $\phi$ & 0.5192 & 0.4772 & 0.5612 \\
$(3 / 5 \mathrm{a}, \mathrm{b}, \mathrm{c})$ & & & & \\
& $\mathrm{a}_{00}$ & 10.20 & 8.636 & 11.77 \\
& $\mathrm{a}_{01}$ & -2.086 & -3.996 & -0.1753 \\
& $\mathrm{a}_{10}$ & -1.089 & -1.125 & -1.054 \\
& $\mathrm{a}_{11}$ & 0.05116 & 0.008507 & 0.09382 \\
& $\mathrm{a}_{20}$ & -2.017 & -2.726 & -1.308 \\
& $\mathrm{a}_{21}$ & 0.8619 & 0.01052 & 1.713 \\
& $\phi$ & 0.5103 & 0.4681 & 0.5525 \\
\hline
\end{tabular}

compared to BWBSdk subzone; and the SBS zone, located west of the Rocky Mountains but south in relation to the BWBS zone, delineates the influence of a wetter and warmer montane boreal climate (mean annual temperature $2.1^{\circ} \mathrm{C}$, mean annual precipitation $646 \mathrm{~mm}$ ) compared to the BWBS zone. Considering growing-season temperature, potential evapotranspiration and growth will generally increase from the BWBSdk to BWBSmw to SBSdw subzone. This trend is supported by site index data (Table 1). Explaining why the temperature regime may cause the height growth patterns at older stages to be different between drier-cooler and wetter-warmer boreal climates is somewhat tenuous.

We cannot explain the delay in faster height growth on good (or high productivity) sites by climatic differences alone because height growth below breast height age 75 is almost identical across the subzones sampled. Black spruce is one of few oxylophytic tree species in North America (Krajina 1969). Its most productive growth occurs on moist and acidic sites. Compared to white spruce, black spruce poorly tolerates nitrogen-, calcium-, and magnesium-rich soils but tolerates acid substrates, such as decaying wood, well (Krajina 1969, Viereck 




Fig. 4. Models (6) and (7) graphed for site indices 5, 10, 15, and 20 up to breast height age 200 .

and Johnston 1990). All study stands originated after wildfires that destroyed acidic forest floor materials, decreased soil acidity, and improved soil nutrient availability. Black spruce growth under these conditions, particularly on nutrient-rich sites, may be edaphically constrained until acidic forest floors have developed and coarse woody debris has accumulated on these sites (Viereck and Johnston 1990). From this point in stand development, the influence of warmer climate becomes effective, and height growth on these productive sites in the BWBSmw and SBSdw subzones becomes faster than in the BWBSdk subzone.

On poor sites, there is again no difference in height growth below breast height age 75 between subzones; however, after this age, growth is faster in drier and cooler climates than growth in wetter and warmer boreal climates, i.e., the reverse compared to good sites. Poor (or low-productivity) sites represent a combination of either water-deficient or waterlogged and nutrient-deficient or nutrient-excess conditions. Considering any of the possible combinations of these edaphic conditions, we cannot explain slower height growth on poor sites in the warmer subzones by climatic differences because when growth is under a strong edaphic control, then climatic influences decrease with increasing extremity of edaphic conditions. We refrain from offering speculative and unsubstantiated explanations. It appears that not all regional differences in height growth pattern of black spruce can be related to climatic factors.

We compared model (7) to other models for black spruce developed in other parts of Canada. These curves included the old curves for British Columbia developed with Alberta data (Alberta Forest Service 1985), new curves for Alberta (Huang et al. 1994), and curves for New Brunswick (Ker and Bowling 1991). Other curves for black spruce have been published (Smith 1984, Smith and Watts 1987, Payandeh and Wang 1994). However, these curves are based on total age and the Smith and Watts (1987) curve has a base age of 100 years. Therefore, these

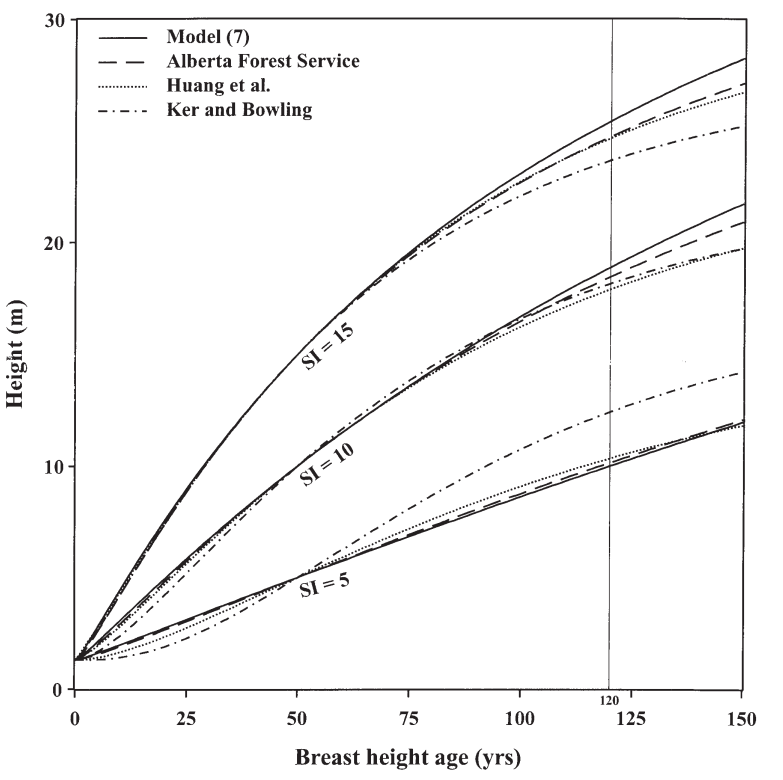

Fig. 5. Model (7), Alberta Forest Service (1985), Huang et al. (1994), and Ker and Bowling (1991) height-age curves for black spruce plotted against breast height age for site indices 5, 10, and $15 \mathrm{~m}$. The vertical line at age 120 indicates the upper limit of the comparison.

curves are not directly comparable to our base age 50 years at breast height curves.

The four curves being compared were plotted for breast height ages 0 to 150 years and for site indices 5,10 , and $15 \mathrm{~m}$ (Fig. 5). The majority of the data for both Alberta curves and model (7) lie between site indices 5 and $15 \mathrm{~m}$ and up to breast height age 120 years. The site indices for the New Brunswick model ranged from 3.5 to $17.3 \mathrm{~m}$ with a maximum age of 203 years; however, the distributional characteristics of the data set was unknown. Therefore, we focussed the comparison on ages up to 120 years given that three of the four curves are not well supported with data beyond 120 years of age. Fig. 5 shows little difference in the height growth patterns exemplified by the four curves. There is no practical difference at site index $10 \mathrm{~m}$. However, the Ker and Bowling curve at site index $5 \mathrm{~m}$ is substantially different from the other curves. The shape of the Ker and Bowling curves at this site index suggests a problem with the functional form rather than true height growth differences. At site index $15 \mathrm{~m}$, the curves are almost identical at young ages but begin to diverge at older ages. The growth similarities indicate either climatic similarities between these regions or low growth plasticity of black spruce in relation to climate. Note that both Alberta curves (Alberta Forest Service 1985, Huang et al. 1994) are very similar for all levels of site index. This comparison suggests that for a given level of site index, black spruce trees will maintain height growth longer in British Columbia than in the other two provinces.

\section{Conclusions}

This study makes available height-age models for black spruce developed with data from British Columbia. Previously, curves like these were not available. Two sets of curves were developed: climate-specific and generalized. The climate-specific models should be used in the six sampled subzones to obtain 
the best estimates of height and/or site index, otherwise the general model should be used. A comparison with other models show that the height growth pattern for black spruce is similar across different regions of Canada.

\section{Acknowledgements}

We thank British Columbia Forest Service staff from the Fort Nelson, Dawson Creek, Fort St. James, Morice, and Vanderhoof Forest Districts for assistance in locating stands suitable for this study. D. New, D. Brisco, B. Collins, and D. Affleck from the University of British Columbia assisted with the sampling and sample preparation. Rob Drummond and Del Meidinger, British Columbia Forest Service provided valuable review comments. Funding for this project was provided by Forest Renewal BC.

\section{Literature Cited}

Alberta Forest Service. 1985. Alberta phase 3 forest inventory: yield tables for unmanaged stands. Alberta Energy and Natural Resources, ENR Rep. No. Dept. 60a.

Banner, A., W. MacKenzie, S. Haeussler, S. Thomson, J. Pojar and R.L. Trowbridge. 1993. A field guide to site identification and interpretation for the Prince Rupert Forest Region. Land Management Handbook No 26. B.C. Min. For., Victoria, B.C.

Carmean, W. H. 1972. Site index curves for upland oaks in the central states. For. Sci. 18: 109-120.

Chen, H.Y.H and K. Klinka. 2000. Height growth models for high-elevation subalpine fir, Engelmann spruce, and lodgepole pine in British Columbia. West. J. Appl. For. 15: 62-69.

DeLong, C., A. MacKinnon and L. Jang. 1990. A field guide for identification and interpretation of ecosystems of the northeast portion of the Prince George Forest Region. Land Management Handbook No. 22, B.C. Min. For., Victoria, B.C.

Greenspan, H.P. and D.J. Benney. 1973. Calculus: an introduction to applied mathematics. McGraw-Hill, Inc. Toronto, ON.

Huang, S., S.J. Titus and T.W. Lakusta. 1994. Ecologically based site index curves and tables for major Alberta tree species. Alberta Environmental Protection, Land and Forest Services, Forest Management Division, Edmonton, AB.

Ker, M.F. and C. Bowling. 1991. Polymorphic site index equations for four New Brunswick softwood species. Can. J. For. Res. 21: 728-732.
Krajina, V.J. 1969. Ecology of forest trees in British Columbia. Ecol. West. N. Amer. 2: 1-146.

Krestov, P.V., K. Klinka, C. Chourmouzis and G. Kayahara. 2000. Classification of mid-seral black spruce ecosystems of northern British Columbia. Scientia Silvica Extension Series Number 26, Forest Sciences Department, University of British Columbia, Vancouver, B.C.

Luttmerding, H., D.A. Demarshi, E.C. Lea, D.V. Meidinger and T. Vold. 1990. Describing ecosystems in the field. $2^{\text {nd }}$ ed. B.C. Min. Environ. and B.C. Min. For., Victoria, B.C.

Mason, R.L., R.F. Gunst and J.L. Hess. 1989. Statistical design and analysis of experiments: with applications to engineering and science. John Wiley \& Sons, Inc. Toronto, ON.

Meidinger, D.V. and J. Pojar. 1991. Ecosystems of British Columbia. Special Report Series 6, B.C. Min. For., Victoria, B.C. Newberry, J.D. 1991. A note on Carmean's estimate of height from stem analysis data. For. Sci. 37: 368-369.

Nigh, G. D. 1997. A Sitka spruce height-age model with improved extrapolation properties. For. Chron. 73: 363-369.

Payandeh, J. and Y. Wang. 1994. Modified site index equations for major Canadian timber species. For. Ecol. Manage. 64: 97-101.

Seber, G.A.F. and C.J. Wild. 1989. Nonlinear regression. John Wiley \& Sons, Inc. Toronto, ON.

Sen, A.K. and M. Srivastava. 1990. Regression analysis: theory, methods, and applications. Springer-Verlag Inc., New York, NY.

Shapiro, S.S. and M.B. Wilk. 1965. An analysis of variance test for normality (complete samples). Biometrika 52: 591-611.

Smith, V.G. 1984. Asymptotic site-index curves, fact or artefact? For. Chron. 60: 150-156.

Smith, V.G. and M. Watts. 1987. An assessment of the structural method of deriving a black spruce site equation. Can. J. For. Res. 17: 1181-1189.

Snee, R.D. 1977. Validation of regression models: methods and examples. Technometrics 19: 415-428.

Thrower, J.S. and J.W. Goudie. 1992. Estimating dominant height and site index of even-aged interior Douglas-fir in British Columbia. West. J. Appl. For. 7: 20-25.

Viereck, L.A. and W.F. Johnston. 1990. Picea mariana (Mill.) B.S.P. black spruce. In R.M. Burns and B.H. Honkala. (eds.). Silvics of North America: Vol. 1. Conifers. pp. 227-237. USDA For. Serv. Agri. Handb. 654, Washington, DC. 